\title{
Effects of Environmental Pollution on the Growth and Existence of Biological Populations Involving H-Function
}

\author{
S. N. Singh* \& Raj Mehta** \\ Abstract: In this paper we discus about 'Effect of environmental pollution on the growth and existence \\ biological populations' in terms of $\mathrm{H}$-function
}

\section{Introduction:}

The $\mathrm{H}$-function of one variable $[1, \mathrm{p} .10]$ is defined as:

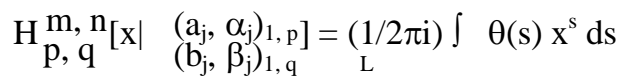

where $\mathrm{i}=\sqrt{ }(-1)$,

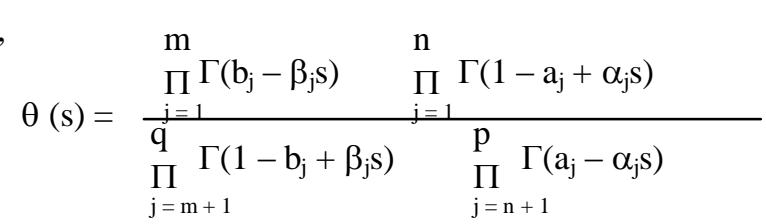

where

$$
\sum_{j=1}^{n} \alpha_{j}-\sum_{j=n+1}^{p} \alpha_{j}+\sum_{j=1}^{m} \beta_{j}-\sum_{j=m+1}^{q} \beta_{j} \equiv M>0,
$$

and $|\arg \mathrm{x}|<1 / 2 \mathrm{M} \pi$.

The deleterious effect of environmental pollution on interacting biological populations depends upon the toxicity and the level of pollutant, the sort of damage it causes to the physiological and biochemical systems of the populations and their environment. To study this situation, in this paper, a mathematical model is presented by considering that the growth rate of species and the carrying capacity of its environment are directly affected by pollution and decrease as the concentration of the pollutant increases. After that a solution of this mathematical equation will also obtained with the help of generalized hypergeometric function.

Since long both various kinds of industrial discharges and wastes, causing damage to our ecosystems, are polluting our atmosphere and the aquatic environment.

*Head, Department of Mathematics Jamtara College Jamtara (Jharkhand)

**Deptt . of Mathematics, Guru Ramdas Khalsa Institute of Science \& Technology,

Barela. Distt. Jabalpur (M.P.) 483001, INDIA

The biological and ecological consequences of pollution in our environment may be considered in several ways depending upon the toxic level of pollutants (acute or chronic) and the ecotoxicological situations. One such situation is where the pollutants can adversely affect the natural resources, thereby influencing the growth of other biological populations, which may be depending upon these resources. The other such situation is where the pollutants can affect directly the species accompanied by rapid injury to the principal physiological and biochemical systems of the organism, and results in lethal toxication, elimination of individual species and populations or causes profound pathological alterations on the level of individual organisms, individual populations, and occasionally, on entire ecosystems which might change the carrying capacity of the environment $[2,3,4,5,6,7]$. Various investigations have been carried out in this direction, both experimentally and mathematically $[2,3,4,5,6,7,8,9,10]$.

In view of the above, in this paper, we have studied the effect of environmental pollution on the growth and existence of two interacting biological populations in the situation where the pollutant causes injury to the principal physiological and biochemical systems of the populations and their environment. To study this situation, a mathematical model is presented here be considering that the growth rate of species and carrying capacity of its environment are directly affected by pollution and decrease as the concentration of the pollutant increases.

\section{Mathematical Model:}

Consider the growth of interacting and dispersing biological species of density $N_{i}(x, t),(i=1,2)$ in a one dimensional linear habitat $05 \mathrm{x} \leq \mathrm{L}$, whose growth rate and the carrying capacity of the environment is decreasing due to the environmental pollution present in the habitat. The dynamical equations governing the 
growth of the species are assumed to be given by the following system of non- linear partial differential equations

$\partial \mathrm{N}_{\mathrm{i}} / \partial \mathrm{t}=\mathrm{N}_{\mathrm{i}} \mathrm{F}_{\mathrm{i}}\left(\mathrm{N}_{1}, \mathrm{~N}_{2}, \mathrm{r}_{\mathrm{i}}(\mathrm{C}), \mathrm{K}_{\mathrm{i}}(\mathrm{C})\right)+\mathrm{D}_{\mathrm{i}}\left(\partial^{2} \mathrm{~N}_{\mathrm{i}} / \partial \mathrm{t}^{2}\right), \mathrm{i}=1,2$

where, $F_{i}\left(N_{1}, N_{2}, r_{i}(C), K_{i}(C)\right)$ determines the interaction function of the species. $r_{i}(C)$ and $K_{i}(C)$ are the intrinsic growth rate and the carrying capacity of the environment respectively which are affected by the concentration $C(x, t)$ of pollutant. The positive constant $D_{i}(i=1,2)$ is the dispersion coefficient of the species. The dynamics of the concentration $\mathrm{C}(\mathrm{x}, \mathrm{t})$ of the pollutant is considered to be given by the following equation

$$
\partial \mathrm{C} / \partial \mathrm{t}=\mathrm{Q}_{0}-\alpha \mathrm{C}+\mathrm{D}_{\mathrm{c}}\left(\partial^{2} \mathrm{C} / \partial \mathrm{x}^{2}\right)
$$

where, $\mathrm{Q}_{0}>0$ is the constant determining the exogenous rate of input of pollutant into the habitat, $\alpha>$ 0 represents the first order decay constant as a result of biological (including consumption by the species), chemical or geological processes. $D_{c}>0$ is the diffusion coefficient of the pollutant. In the formulation of the model it has been assumed that the organismal uptake of the pollutant is proportional to the concentration of the pollutant present in the environment of the population. On the basis of the mathematical model (3) the solution of this mathematical equation will be obtained with the help of $\mathrm{H}$-function of one variable in the subsequent part of this section.

\section{Result In Terms Of H-Function:}

Choose concentration $\mathrm{C}(\mathrm{x}, \mathrm{t})$ in terms of $\mathrm{H}$-function as

$$
\mathrm{C}(\mathrm{x}, \mathrm{t})=\mathrm{H}_{\mathrm{p}, \mathrm{q}}^{\mathrm{m}, \mathrm{q}^{\mathrm{n}} \mathrm{zx}^{\sigma} \mathrm{t}^{\mu} \mid \begin{array}{l}
\left(\mathrm{a}_{\mathrm{j}}, \alpha_{\mathrm{j}}\right)_{1, \mathrm{p}} \\
\left(\mathrm{b}_{\mathrm{i}}, \beta_{\mathrm{i}}\right)_{1, \mathrm{q}}
\end{array}}
$$

where $\sigma>0, \mu>0,|\arg \mathrm{z}|<1 / 2 \pi \mathrm{A}$, where $\mathrm{A}$ is given in (1.2.38).

Now differentiate it with respect to $x$ and $t$ partially, we get

and

$$
\partial \mathrm{C} / \partial \mathrm{t}=(1 / \mathrm{t}) \mathrm{H}_{\mathrm{p}+1, \mathrm{q}+1}^{\mathrm{m}, \mathrm{n}+1} \quad\left[\left.\mathrm{zx}^{\sigma} \mathrm{t}^{\mu}\right|_{\left(\mathrm{b}_{\mathrm{j}}, \beta_{\mathrm{j}}\right)_{1, \mathrm{q}},(1, \mu)} ^{(0, \mu),\left(\mathrm{a}_{\mathrm{j}}, \alpha_{\mathrm{j}}\right)_{1, \mathrm{p}}}\right]
$$

$$
\left(\partial^{2} \mathrm{C} / \partial \mathrm{x}^{2}\right)=\left(1 / \mathrm{x}^{2}\right) \mathrm{H} \begin{aligned}
& \mathrm{m}, \mathrm{n}+1 \\
& \mathrm{p}+1, \mathrm{q}+1
\end{aligned}\left[\mathrm{z} \mathrm{x}^{\sigma} \mathrm{t}^{\mu} \mid \begin{array}{l}
(0, \sigma),\left(\mathrm{a}_{\mathrm{j}}, \alpha_{\mathrm{j}}\right)_{1, \mathrm{p}} \\
\left(\mathrm{b}_{\mathrm{j}}, \beta_{\mathrm{j}}\right)_{1, \mathrm{q}},(1, \sigma)
\end{array}\right]
$$

Now after using (4), (5) and (6) in (3), we get following result

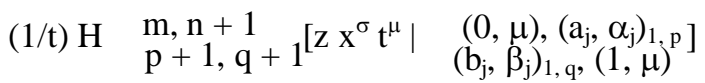

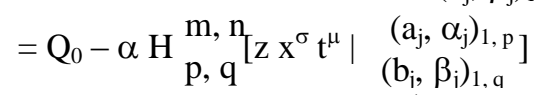

$$
\begin{aligned}
& +D_{C}\left(1 / x^{2}\right) H_{p+1, q+1^{m}}^{m, n+1} x^{\sigma} t^{\mu} \mid \begin{array}{l}
(0, \sigma),\left(a_{j}, \alpha_{j}\right)_{1, \beta} \\
\left(b_{j}, \beta_{j}\right)_{1, q},(1, \sigma)^{1}
\end{array}
\end{aligned}
$$

where $\sigma>0, \mu>0,|\arg z|<1 / 2 \pi M$, where $M$ is given in section $M$.

\section{Special Cases:}

On specializing the parameters, H-function may be reduced to G-function, Lauricella's functions Legendre functions, Bessel functions, hypergeometric functions, Appell's functions, Kampe de Feriet's functions and several other higher transcendental functions. Therefore the result (7) is of general nature and may reduce to be in different forms, which will be useful in the literature on applied Mathematics and other branches.

\section{References}

[1]. Srivastava, H. M., Gupta, K. C. and Goyal, S. P.: The H-function of one and two variables with applications, South Assian Publishers, New Delhi, 1982.

[2]. Aubert, M. and Aubert, J.: Pollutions et Amenagement Des Rivages, C. E. R. B. O. M., 1973, p. 308.

[3]. Charles, N. and Haas, J.: WPCF 53 (1981), 378-86.

[4]. Hallam, T. J. and Deluna, J. L.: J. Theor. Biol. 109 (1984), 411-29.

[5]. Hari, P. Raunemaa, T. and Hautojarvi, A.: Atmospheric Environment 20 (1986), 129-37.

[6]. James N Woodman and Ellis B. Cowling: Environ. Sci. Tech. 21 (1987), 120-26.

[7]. Jensen, A. L. and Marshall, J. S.: Environmental Pollution (Series A) 28 (1982), 273-80.

[8]. Mironov, O. G.: Biological Resources of the Sea and Oil pollution, pishechevaya Promyshlennost, Moscow, $1972 .$, p. 105

[9]. Patin, S. A.: Pollution and the Biological Resources of the Oceans, Butter Worth Scientific, London, 1982.

[10]. Smith A. Nelson: Advances in Marine Biology, Academic Press, London, 1970, pp. 215-306. 